\title{
A short note on honorifics and personal articles in Spanish and Catalan. Consequences for the theory of proper names
}

\author{
Andrés Saab \\ IIF-SADAF-CONICET \& University of Buenos Aires \\ andres.saab@uba.ar
}

Received: 07-04-2021

Accepted: 25-04-2021

Published: 27-04-2021

How to cite: Saab, Andrés. 2021. A short note on honorifics and personal articles in Spanish and Catalan. Consequences for the theory of proper names. Isogloss. Open Journal of Romance Linguistics 7, 6:1-14.

DOI: https://doi.org/10.5565/rev/isogloss.142

\begin{abstract}
Building on recent findings in Bernstein et al. (2019), regarding the syntactic distribution of personal articles in Catalan and honorifics in Spanish, I propose that they are pure expressives (in Potts' (2005) sense) that take an entity as argument and return the same entity at the at-issue level and a conventionally implicated proposition in a parallel meaning dimension. If this analysis turns out to be correct, the expressive / proper name interaction in these languages will constitute a new piece of evidence against the predicative analysis of proper names.
\end{abstract}

Keywords: honorifics; personal articles; Catalan; Spanish; proper names; expressives.

I would like to thank two anonymous reviewers whose comments and criticism were crucial for helping me to strengthen my argument and to clarify many implicit assumptions in the original version. My gratitude extends to Fernando Carranza, Nicolás Lo Guercio, Carlos Muñoz Pérez, Francisco Ordóñez, Eleonora Orlando, Francesc Roca, Cilene Rodrigues, Avel-lina Suñer and Matías Verdecchia. I am also very thankful to Vero Ferri for proofreading this paper. As usual, I am the sole legitimate owner of any mistake or contradiction. 
In a recent study, Bernstein et al. (2019) show that personal articles denoting familiarity in some varieties of modern Catalan (e.g., en Paco, na Carme, see (1)) and the honorific don/doña denoting respect/formal distance in Spanish (e.g., Doña Ana, Don Luis, see (2)) have the same diachronic origin: the Latin noun dominus, which was used as an honorific title only reserved to the royalty (see (3)). ${ }^{1}$

\section{Balearic Catalan: ${ }^{2}$}
a. $\quad E n$
Pere ha
arribat tard.
PA.MASC
P. has
arrived late
'Pere has arrived late.'
b. $\quad N a$
Maria ha
PA.MASC M. has
'María has arrived late.'
arribat tard.
arrived late

[Bernstein et al. (2019), p. 84, ex. (2)]

Glosses: $\mathrm{AUX}=$ auxiliary, $\mathrm{DIM}=$ diminutive, $\mathrm{DOM}=$ differential object marking, $\mathrm{FEM}=$ feminine, $\mathrm{HON}=$ honorific, $\mathrm{INF}=$ infinitive, $\mathrm{MASC}=$ masculine, $\mathrm{PA}=$ personal article, $\mathrm{PL}$ $=$ plural, $\mathrm{SG}=$ singular.

Avel-lina Suñer and Francesc Roca pointed out to me that the en/na alternation is only present in some variants of Balearic Catalan. In colloquial Central Catalan, the definite articles $e / / l a$ 'the.MASC/the.FEM' are used instead, with exactly the same familiarity effects. In more formal registers of the same dialect and in other registers of Eastern Catalan (e.g., Figueras, Alt Empordà), the alternation is en-l'/la, with the same familiarity effect again. Throughout this paper, I will use the Balearic alternation, but I think that the point I will make generalizes to other article alternations in other Catalan dialects. Probably, the same analysis extends to many Spanish dialects as well, in which articles optionally occur with proper names in a very productive way. In my own dialect, for instance, using the definite article with a referential proper name (i.e., not a predicative one, see (13)) also rises the familiarity effect, e.g., Esta tarde voy a ver al Juan 'This afternoon I will see the.MASC Juan'. Francisco Ordóñez (p.c.) has reported the same uses in other Spanish dialects. He has also informed me that in some central Peninsular dialects, there is an asymmetry between masculine and feminine proper names: only feminine names allow for the expressive article with the familiarity effect. The same asymmetry is attested in some Northern Italian dialects. In Argentinian Spanish, similar facts are also attested by the productive use of feminine surnames with articles for famous actresses or divas but not actors (e.g., la Legrand, la Loren, la Callas vs. \#el De Niro, \#el Alcón, \#el Mastroiani, although el Diego for referring to Maradona is perfect and very common). These uses also seem to express familiarity, since the actresses referred to are supposed to be close to their audiences' hearts. Even if further research is needed in order to understand many of these patterns, I am pretty convinced that an expressive analysis along the lines to be proposed here for Balearic Catalan would generalize to these other uses of the definite article with proper names in other Romance languages. A first piece of evidence pointing out in this direction is that, for instance, in my own dialect the use of the expressive article is ungrammatical in the plural (i.e., Esta tarde voy a ver a los Juanes 'This afternoon I will see the.MASC.PL Juanes' has only a predicative reading, not a referential one). 
(2)
Spanish:

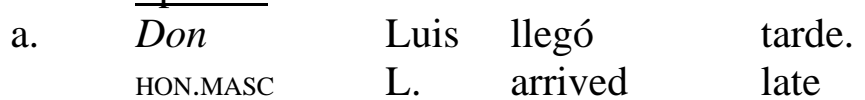

'Mr. Luis arrived late.'

b. Doña María llegó tarde.

HON.FEM Maria arrived late

'Mrs. María arrived late.'

(3) dominus $>$ ne $>$ en-na (Catalan)

dominus $>$ don-doña (Spanish)

[Bernstein et al. (2019), p. 84, ex. (1)]

As for personal articles in Balearic Catalan, Bernstein et al. (2019) discuss a series of intriguing properties regarding their morpho-syntactic distribution. First, unlike regular articles, the personal article only occurs in the singular:
a. Personal article:
en (masc.sg), *ens (masc.pl)
na (fem.sg), *nes (fem.pl)
b. Definite article:

$$
\begin{aligned}
& \text { el (masc.sg), els (masc.pl) } \\
& \text { la (fem.sg), les (fem.pl) }
\end{aligned}
$$

[Bernstein et al. (2019), p. 90, ex. (6)]

Second, it is strictly adjacent to the name:

(5)
a. *en propi Pere
PA.MASC same Pere
b. el propi professor
the.MASC same professor
'the same professor'

[Bernstein et al. (2019), p. 91, ex. (7)]

Third, it disallows restrictive modification:

(6)
a. *en Pere que va arribar ahir PA.MASC P. that AUX arrive.INF yesterday
b. el Pere que va arribar ahir the.MASC P. that AUX arrive.INF yesterday 'the Pere that arrived yesterday'

[Bernstein et al. (2019), p. 91, ex. (8)-(9)]

A very similar distribution is found with the honorific don/doña in Spanish when it modifies proper names: ${ }^{3}$ 
(7) don (masc.sg), *dones (MASC.PL)

doña (fem.sg), *doñas (FEM.PL)

$\begin{array}{lll}* \text { don } & \text { mismo } & \text { Luis } \\ \text { HON.MASC } & \text { same } & \text { Luis }\end{array}$
a. $\quad * d o n$ HON.MASC L. that
b. el Luis
Luis que llegó ayer
L. that arrived yesterday
the L. that arrived yesterday
'the Luis who arrived yesterday'
[adapted from Bernstein et al. (2019), p. 91, ex. (12)-(14)]

According to Bernstein et al., this distribution, among other relevant facts, justifies the following syntactic analysis, according to which the personal article in Catalan and the Spanish honorific are low classifiers: ${ }^{4}$

$$
\text { [DP [D el-la }] \ldots \text { [ClassP [Class en-na/don-doña] [NP N ] ] ] }
$$

[Bernstein et al. (2019), p. 93, ex. (15)]

I subscribe to many of the essential aspects of this approach, in particular, regarding the conclusion that the personal article and the honorific in each of the relevant languages is generated in a low position as an NP sister. But what about the semantic derivation? At least in a semantic sense, I contend that rather than classifiers, personal articles and honorifics are triggers for conventional implicatures (CI) in a nonat-issue meaning dimension. More concretely, personal articles in modern Catalan and the honorific don/doña in modern Spanish are pure expressives in Potts' (2005) sense, i.e., functions that take an entity as argument and return the same entity at the at-issue level and a conventionally implicated proposition in a parallel meaning dimension. The relevant axiom under which expressive phrases are interpreted is CI Application, as defined in (11) below (Potts 2005: 64). In this definition, the bullet $\bullet$ is Potts' metalogical operator to separate meaning dimensions, the dotted circles indicate optional CI meanings, and the superscripts on the variables for semantic types, $\tau^{a}$ and $\tau^{c}$, are used to express meanings in the at-issue dimension and the CI dimension (i.e., the conventional implicature dimension), respectively:

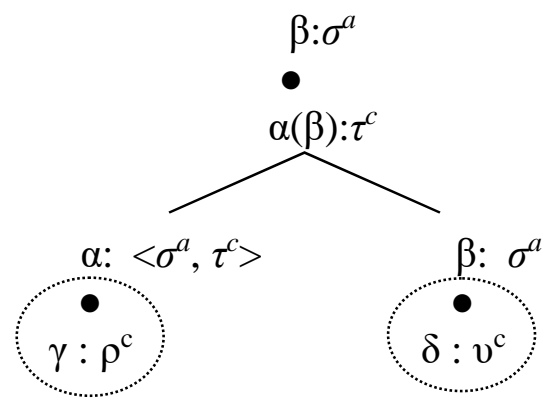

modifies an empty noun, i.e., there is also a pronominal use of don/doña. In those cases, pluralization is not impossible (e.g., Escúchenme, doñas 'Listen, HON.FEM.PL'). 
Conceiving of honorifics in Spanish and personal articles in modern Catalan as pertaining to the class of Potts' expressives, we can now write the relevant lexical entries. As for the honorific, the lexical entry I propose is given in (12a). In (12b), I provide a first rough illustration of the semantics of doña applied to the proper name Ana:

$$
\begin{aligned}
& \text { a. Lexical entry for don/doña: \don/doña } \rrbracket=\lambda x \text {. Respect }\left(s^{\mathrm{c}}, x\right):\left\langle e^{a}, t^{c}\right\rangle \\
& {\left[s^{\mathrm{c}}=\text { speaker of the context }\right]}
\end{aligned}
$$

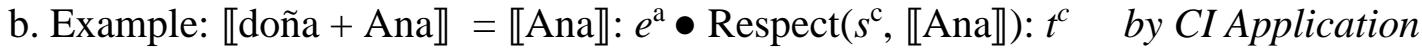

Now, as for the syntax in which this expressive participates, there are two differences with respect to Bernstein et al.'s original analysis. First, I will use the label ExP (for Expressive Phrase) instead of ClassP, because of the reasons already adduced and the ones we will see in a moment. In principle, given the semantic import that differentiates expressives from classifiers, this is something more than a labeling difference. At any rate, this is a lexical difference, which does not affect the syntactic distribution of these items, which, I assume, is like Bernstein et al. propose. ${ }^{5}$ Second, following Saab and Lo Guercio (2020), I contend that referential uses of proper names (e.g., bare proper names in contexts like Anne arrived late) do not project a Number Phrase (NumP). In this respect, bare referential uses contrast with predicative uses of proper names (i.e., The Anne I know arrived late), which do project NumP. Following Acquaviva (2007), Saab and Lo Guercio correlate presence or absence of $\mathrm{Num}^{0}$ with the semantic type of the nominal phrase: $\langle e, t\rangle^{a}$ or $e^{a}$ type, respectively.

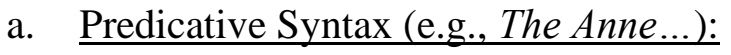

b. Referential Syntax (e.g., Anne):
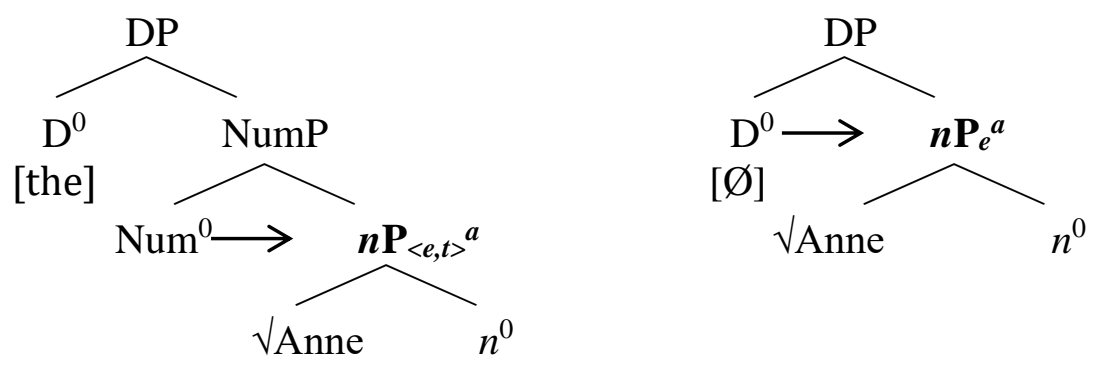

This analysis aims at capturing the basic fact that in order to be a true nominal predicate, proper names, which start their syntactic-semantic life as denoting in the $e^{a}$ type, need selection by the Num head. Absence of $\mathrm{Num}^{0}$ results in the absolute impossibility for referential uses of proper names to be pluralized:

$\begin{array}{lllll}\text { a. } & * \text { Juanes } & \text { llegaron } & \text { a } & \text { la fiesta. } \\ \text { J.PL } & \text { came.3PL } & \text { to } & \text { the party }\end{array}$

But as far as I can tell, my analysis is perfectly compatible with an adjunction approach, according to which expressives are adjoined to the $n \mathrm{P}$ level or some related low position. In principle, my analysis only requires sisterhood between the expressive and the proper name in order to feed CI Application. Thanks to Cilene Rodrigues for calling my attention to this alternative. 

b. Juan llegó a la fiesta.
J.SG came.3PL to the party
'Juan came to the party.'

Of course, a predicative use of a proper name can be pluralized because of the presence of a $n \mathrm{P}$ selected by a Num head. Presence of $\mathrm{Num}^{0}$ correlates not only with number marking but with the same realization of the D head as in regular DPs, as well:
a. Los Juanes que conozco llegaron a la fiesta. the.PL J.PL that know.1SG came.3PL to the party 'The Juanes I know arrived at the party.'
b. El Juan que conozco llegó a la fiesta. the.SG J.SG that know.1SG came.3SG to the party 'The Juan I know arrived at the party.'

On this analysis, proper names are either direct referential expressions or mere predicates because of their particular syntactic distribution.

Having clarified the similarities and differences with Bernstein et al.'s analysis, let us see now how the syntax and the semantics of Spanish proper names modified by honorifics look like once the lexical entry in (12a) is assumed:

\section{Syntax and semantics for Spanish honorifics (e.g., Doña Ana):}

a. Syntax:

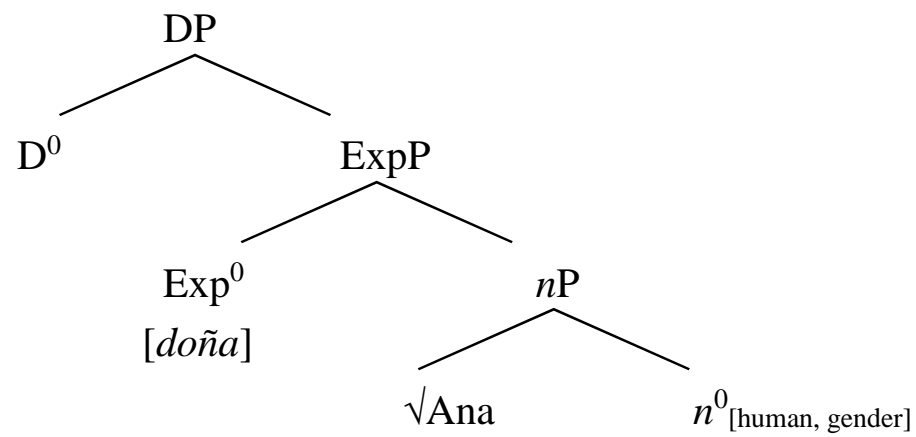

b. Semantics:

Ana: $e^{a}$

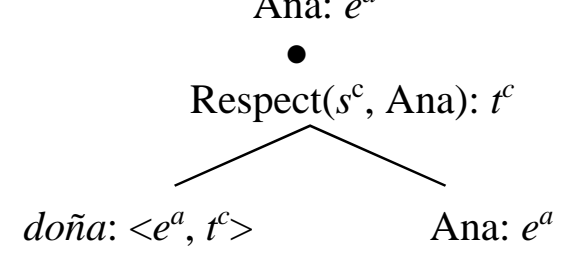

The analysis of personal articles in modern Catalan is very similar except for a difference in the content of the CI meaning, which I schematically model as a Familiar predicate taking the proper name meaning and the parties of the conversation as arguments. Thus, a reasonable paraphrase for the proposition implicated would be something along these lines: the individual denoted by the proper name is familiar to the interlocutors of the context:

a. Lexical entry for $e n / n a: \llbracket \mathrm{en} / \mathrm{na} \rrbracket=\lambda x$. Familiar $\left(I^{\mathrm{c}}, x\right):\left\langle e^{a}, t^{c}\right\rangle$

$$
\left[I^{\mathrm{c}}=\text { interlocutors of the context }\right]
$$

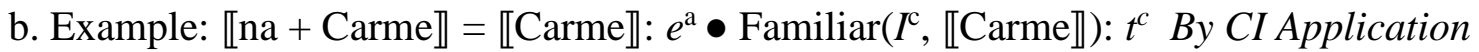


The entry in (17a) just formalizes what Bernstein et al. say regarding the familiar meaning that the personal article introduces, which sharply contrasts with the meaning that its counterpart without the article has:
Familiarity effect: ${ }^{6}$
a. Chomsky ha publicat un altre llibre.
Chomsky has published an other book

b. En Chomsky ha publicat un altre llibre. ART.MASC Chomsky has published an other book 'Chomsky has published another book.'

[Bernstein et al. (2019), p. 102, ex. (36)]

In their words:

"The semantic difference between [18a] without a personal article and [18b] with one is that the latter example expresses pragmatically the idea that the speaker is familiar with Noam Chomsky. Included is an implicature that the hearer is also familiar with him. This meaning is not the default for [18a], though it is a possible interpretation. Modern Spanish don/doña, unlike modern Catalan en/na, encodes formality or politeness, and never familiarity."

[Bernstein et al. (2019), p. 102; my emphasis]

The lexical entry in (17a) captures this meaning intuition as a conventional implicature introduced by the expressive article, which takes an individual as argument, returns the same individual at the at-issue level and adds the familiarity conventional implicature at the CI dimension. Note that an important difference with Bernstein et al. is that on my analysis, this expressive meaning is a semantic convention not a pragmatic one.

With the lexical entry in (17a) as a starting point, the syntactic and semantic analyses for personal articles follow now in a routinary way:

\section{Syntax and semantics for personal articles in Modern Catalan (e.g., Na Carme):}

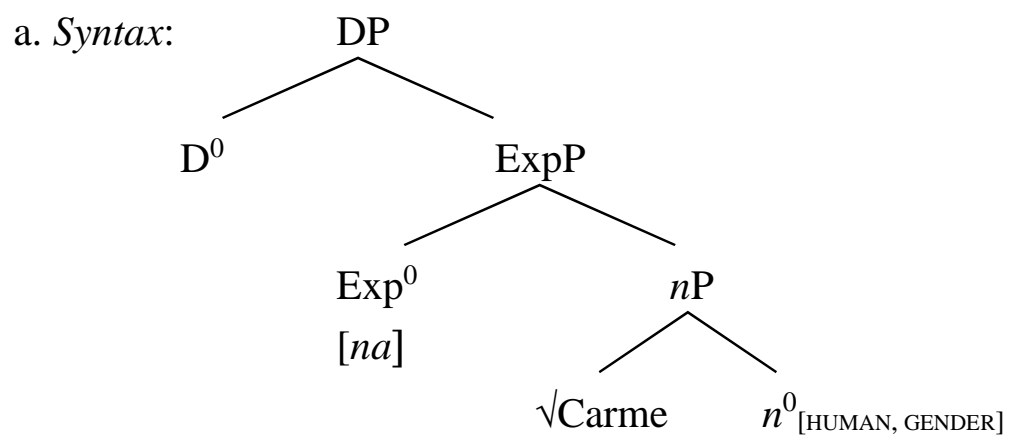

6 See Brucart (2002) for a similar observation regarding the familiarity effect. 
b. Semantics:

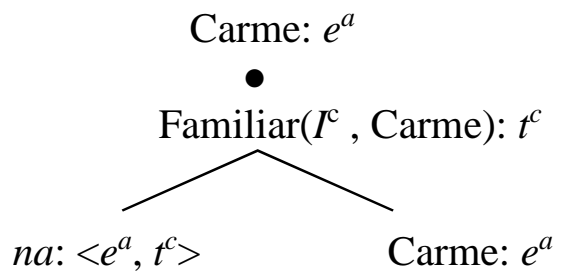

Crucial evidence in favor of an expressive analysis for Spanish honorifics and personal articles in modern Catalan is that they pass all the tests that diagnose expressivity at the CI dimension (see Potts 2005). Let us focus on hyper-projectability and speaker-oriented tests, which are among the more robust diagnostics for detecting expressivity:

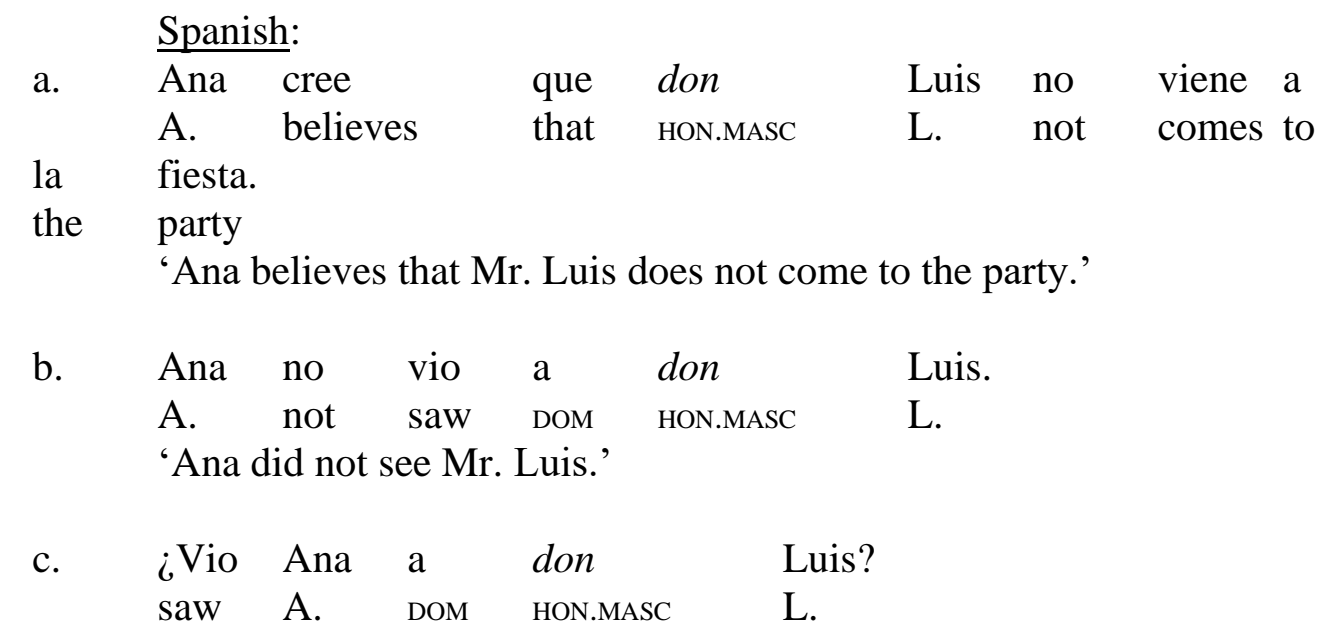

d. $\quad$ Si don

if HON.MASC

Luis está solo, sería

bueno

visitarlo.

L. is

alone, would.be

good

visit.INF=HIM

'If Mr. Luis is alone, it would be good to visit him.'

(21)
Balearic Catalan: ${ }^{7}$
a. N'Anna creu
PA.FEM-A. believes
que $n a$
that PA.FEM
Carme ha
C. has
'Anna believes that Carme has arrived late.'
b. N'Anna no va veure en Lluís.
PA.FEM-A. not AUX See.INF ART.MASC L.
'Anna did not see Lluís.'

arribat tard.

$7 \quad$ I am thankful to Francesc Roca and Avel-lina Suñer for their judgments and help with the Catalan examples. As noted in footnote 2, these examples only correspond to Balearic Catalan, but the same hyper-projectability effects plus the speaker-oriented meaning are attested in Central and Eastern varieties but with the $e / / l a$ alternation and the en-l'/la alternation respectively. 


$\begin{array}{lll}\text { c. Va veure en } & \text { Lluís, n'Anna? } \\ \begin{array}{l}\text { AUX. see.INF } \\ \text { 'Did Anna see Lluís?' }\end{array} & \text { L. } & \text { PA.FEM-A. }\end{array}$

$\begin{array}{llllll}\text { d. } & \text { Si en Lluís està sol, seria } & \text { bo } & \text { visitar-lo. } \\ \text { if } & \text { PA.MASC L. } & \text { is alone would.be } & \text { good } & \text { visit.INF-HIM } \\ \text { 'If Lluís is alone, it would be good to visit him.' } & & \end{array}$

The examples in (20a) and (21a) demonstrate (i) that familiarity/honorific meanings project out of the propositional attitude predicate, and (ii) that both meanings are speaker-oriented, i.e., it cannot be the case that the respect or the familiarity meanings are not attributed to the speaker of the context or the interlocutors of the speech act. Similar results obtain in (20-21b), (20-21c) and (20-21d). Hyperprojectability effects are straightforwardly captured under Potts' bidimensional logic, which is indeed particularly designed for accounting for those effects. In a nutshell, meanings pertaining to the at-issue dimension like the kind of meaning introduced by truth-conditional operators cannot affect meanings pertaining to the CI-dimension. In turn, the speaker-oriented property is an intrinsic convention of expressive items and, as such, must be modeled in the lexicon, as I did with the lexical entries in (12a) and (17a).

The proposed syntactic and semantic analyses derive the three particularities of personal articles in Catalan and Spanish honorifics found in Bernstein et al. First, their incompatibility with pluralization (see (4) and (7)) follows from the very nature of proper names as numberless DPs, exactly as proposed for independent reasons in Saab and Lo Guercio (see the tree in (13b)). Second, the adjacency effects in both languages (see (5) and (8)) are captured in the same way as in Bernstein et al., i.e., from the merge position of this sort of expressives as strict $n \mathrm{P}$ sisters. In this respect, Bernstein et al.'s finding is a particularly important one, since it forces us to give up the common idea that personal articles in Catalan are D projections (see, for instance, Matushansky 2006). Note that related to this, taking personal articles and honorifics as pertaining to the class of Potts' expressives adds a clear motivation for why they have the particular syntactic distribution noticed by Bernstein et al. Concretely, the expressive and the proper name in Spanish and Catalan have to be in the required sisterhood relation that feeds CI Application (see (11)). Finally, absence of restrictive modification is directly captured under an analysis according to which proper names are not predicates, but direct referential expressions. Therefore, the ungrammaticalities in (6a) and (9a) are fully reduced to the impossibility of restrictive modification with bare proper names (e.g., *Anne I know arrived late). In order for restrictive modification to be allowed, the proper name has first to be converted into a predicate by the introduction of a Number head, like in examples (6b) and (9b), in which the presence of true determiners is correlated with presence of a NumP projection (cfr. (9b) with los Luises que llegaron ayer 'the.PL Luis.PL who arrived yesterday').

Now, if what I have proposed here turns out to be correct, the syntax and semantics of personal articles in Catalan and Spanish honorifics would constitute another important piece of evidence against the predicative analysis of proper names (see, in particular, Matushansky 2006, 2008). In effect, on my analysis, personal articles in Catalan and Spanish honorifics are expressive functors taking entity denoting expressions as arguments. This approach directly explains why, then, honorifics and personal articles are fully incompatible with true predicates denoting in $\langle e, t\rangle^{a}$ (or $\langle s$, $\left.\langle e, t\rangle\rangle^{a}\right)$ : 

a. * Llegó el don médico. arrived the HON.MASC doctor 'The doctor arrived.'
b. Va arribar el/*en professor. AUX. arrive.INF. the.MASC/PA.MASC professor 'The professor arrived.'

The impossibility of combining Spanish honorifics and Catalan personal articles with true predicates boils down to a straightforward type mismatch, in which the predicate denoting in $\langle e, t\rangle^{a}$ cannot satisfy the $e^{a}$ type argument that the expressive functor requires. Importantly, the same facts cannot be explained arguing that the predicate that médico or professor denotes cannot be modified by such low expressives, since it is not the set of professors or doctors which the speaker honors or is familiar with but a particular individual. Put differently, the problem is clearly related with syntactic combination of semantic types not with their content. As we will see in a moment, other expressives like maldito 'damn' has the same superficial distribution as personal articles or honorifics, but the result is perfect, as the following example shows:

$\begin{array}{llllll}\text { El } & \text { maldito } & \text { profesor } & \text { me } & \text { desaprobó } & \text { de nuevo. } \\ \text { the } & \text { damn } & \text { professor } & \text { CL.1SG.ACC } & \text { failed } & \text { again }\end{array}$

'That damn professor failed me again.'

As is clear, the expressive does not affect the set of professors but a particular individual or the event of being failed by a certain professor (see footnote 8 for some additional discussion on this semantic effect). So, the difference that explains why the relevant sentences in (22) are ungrammatical but the one in (23) is perfect must be found in the semantic type of the argument that maldito and don require and nothing else. In sum, for this and other reasons adduced in this note, it is evident that if proper names were predicates, the pattern briefly discussed here would remain mysterious.

Before concluding, let me comment on three important observations made by two anonymous reviewers. First, as noted by one of them, both don/doña and en/na are compatible with common nouns, but with interesting restrictions. Here are some Spanish examples:

$\begin{array}{llll}\text { doña } & \text { calores, } & \text { don } & \text { risitas... } \\ \text { HON.FEM } & \text { heats } & \text { HON.MASC } & \text { giggles }\end{array}$

[Reviewer's examples]

Interestingly, on these uses, don/doña must be interpreted as uses of a given proper name, in which the property expressed by the common noun is taken as a distinctive trait of the individual, in a way similar to nicknames (e.g., El Pulga 'the Flea[masc]', La Mona 'The Monkey[fem]'). As the reviewer points out, the argument against the predicative analysis still holds. Yet, I think that we can strengthen the reviewer's point even further by saying that the facts can be taken as giving further support to the proposed analysis: in order to be licitly combined with don/doña, a common noun has first to be syntactically converted into a proper name, which in Saab and Lo Guercio's approach means to force such a common noun to participate in a numberless DP like (13b). 
Another reviewer makes the observation that "on the notion of proper names as a numberless DP, which presumably would derive the lack of plural instances of en/na or don/doña, it is not completely obvious why the mechanism that derives los Alfredos is not available for deriving *dones Alfredos." The claim that dones Alfredos "Mr. Alfreds' is impossible is correct, but let me add that in order to get a plural proper name, an instance of $\mathrm{Num}^{0}$ must be added to the internal structure of a given proper name. As we already know, adding $\mathrm{Num}^{0}$ results, in turn, in a regular DP structure in which the $\mathrm{D}^{0}$ head must be overtly realized (at least, under the definite reading). So, the relevant minimal pair would be as follows:

$\begin{array}{llllll}\text { a. } \begin{array}{l}\text { Los Alfredo(s) que conozco } \\ \text { the Alfred.(PL) }\end{array} & \begin{array}{l}\text { llegaron } \\ \text { that know.1SG }\end{array} & \begin{array}{l}\text { tarde. } \\ \text { arrived }\end{array} \\ \text { 'The Alfreds I know arrived late.' } & & \\ \text { b. } & \text { *Los dones } & \text { Alfredo(s) que } & \text { conozco } & \text { llegaron } \\ \text { the HON.MASCPL } & \text { Alfred.(PL) that } & \text { know.1SG } & \text { arrived } \\ \text { tarde. } & & & & & \\ \text { late } & & & & & \end{array}$

So, the reviewer's point still holds, which is in fact a very welcome result for my analysis here and Saab and Lo Guercio's general approach to the syntax and semantics of proper names. The reason is simple: merging $\mathrm{Num}^{0}$ right above $n \mathrm{P}$ converts this $n \mathrm{P}$ into a property of the $\langle e, t\rangle^{a}$ type (i.e., a semantic predicate of some sort). The resulting semantic object is not a suitable semantic argument for the don/doña expressive functor, which requires a semantic object of the $e^{a}$ type, not of the $\langle e, t\rangle^{a}$ one. That is to say, the ungrammaticality of (25b) follows as a type mismatch, transparently predicted by the proposal made here.

Finally, the same reviewer correctly points out that "it would be useful to explore examples like (26), where the CI contribution by maldita 'damn' seems to contradict that of $d o \tilde{n} a$, a somewhat unexpected possibility if both are speakeroriented":

$\begin{array}{llll}\text { Vimos a la maldita } & \text { doña } & \text { Ana } \\ \text { saw DOM the damn } & \text { HON.FEM } & \text { A. } \\ \text { 'We saw the damn } & \text { Mrs. Ana.' } & & \end{array}$

[Reviewer's example]

Note first that the example seems to challenge what I have just said with respect to the impossibility of (25b), namely, that don/doña cannot occur in a predicative context (see (13a)). Keep this in mind and, for the time being, accept the reviewer's claim that we indeed have two expressives interacting in the environment of a proper name. My first reaction to this is that even putting aside possible ironic uses, there is no incompatibility between the two meanings: one can show distance or respect to someone without implicating that one likes such a person. ${ }^{8}$

$8 \quad$ I am shamelessly simplifying the picture here in order to reconstruct the reviewer's argument. As is well-known, pure expressives of the damn type introduce important complications for a strict compositional analysis of sentences containing such expressives. The problem is easy to pinpoint: if one says I do not find the damn keys!, one is not in a particular heightened emotional state regarding the relevant keys, but regarding the whole event. This problem is dubbed argument extension in Gutzmann (2019), a terminological decision that makes clear reference to the intriguing fact that 
However, beyond this possible objection and my reaction above, the reviewer's example is relevant in other respects as well, since it highlights putative licit interactions between different types of expressives and bears, consequently, on the main thesis of this paper, namely, that personal articles and honorifics take individuals as arguments, not properties. ${ }^{9}$ Therefore, the next point to notice regarding such potential interaction is that maldita, which essentially behaves like English damn in the relevant respects (see Saab and Carranza 2021), should not combine with proper names. This is so, because as we noted above with respect to the example in (23), expressives of the damn type take properties as arguments, not entities, and return a conventionally implicated proposition expressed through Potts' $B A D$ function, which is vaguely translated as the function stating that "the speaker is in a heightened emotional state regarding X", where $X$ is the plural individual composed of all members of the input set (see Potts 2005: 167-168). To see how expressives of the damn type work, consider the following syntax for a Spanish expressive DP like los malditos neoliberales 'the damn neoliberals':

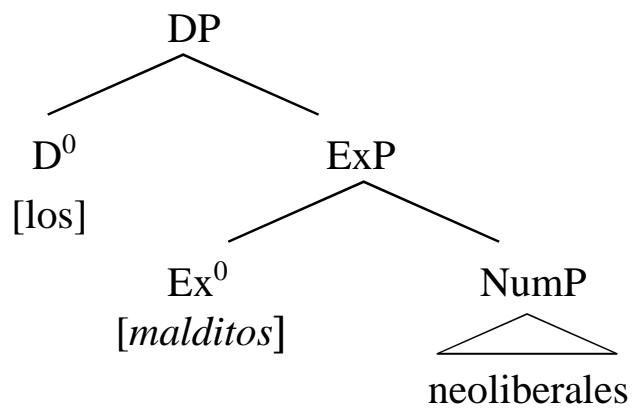

It seems then that these expressives are in complementary distribution with honorifics regarding the type of argument each can take. Put differently, assuming with Potts that maldito denotes in $\left\langle\left\langle e^{a}, t^{a}\right\rangle, t^{c}\right\rangle$ (i.e., it takes an $\langle e, t\rangle^{a}$ argument at the atissue dimension and returns the same argument plus a CI meaning), the relevant interpretative axiom is CI Application, like in the case of honorifics and personal articles, with the already noticed difference in the semantic type of the argument for the functor:

the semantic arguments of such expressives do not necessarily correspond to their syntactic arguments. I refer the reader to Gutzmann for an attempt to reconcile argument extension effects with compositionality.

$9 \quad$ Cilene Rodrigues (p.c.) calls my attention to other potential relations among expressive operators, like, for instance, the interaction that can be deduced from Don Andrecito 'HON.MASC.SG Andrés-DIM', in which don modifies a proper name already modified by a diminutive suffix. This combination produces a funny meaning, in which formal distance or admiration by the speaker part is connected to intimate affection by the speaker part, as well. This looks, then, like a true interaction between two expressive operators and, as far as I can tell, it would be straightforwardly derived under Potts' framework by letting each expressive operates on the proper name at-issue meaning to deliver two CI meanings with the funny effect already commented. Interestingly, diminutive suffixes on common nouns would primarily affect at-issue meanings on top of having an additional affective meaning (e.g., mesita 'table.DIM' regularly denotes a small table plus some affective meaning). This difference would also follow from the different semantic types proper names and common nouns have. 


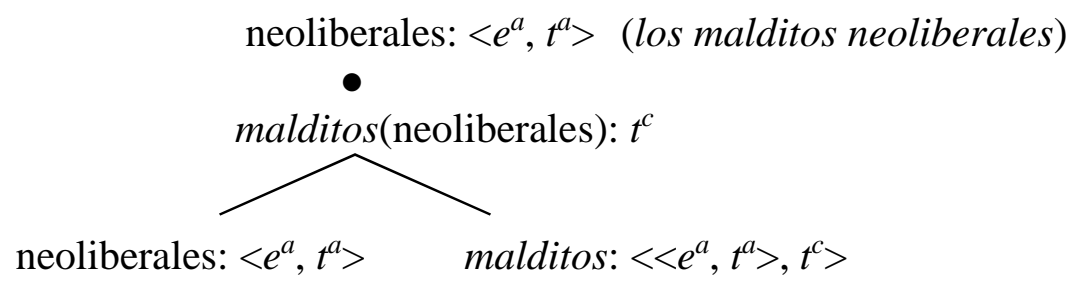

[modeled after Potts 2005: 166]

Taking both Potts's approach to pure expressives and my own analysis for Spanish honorifics for granted, the prediction is straightforward: the expressive maldito cannot take referential proper names as arguments. And this is borne out:

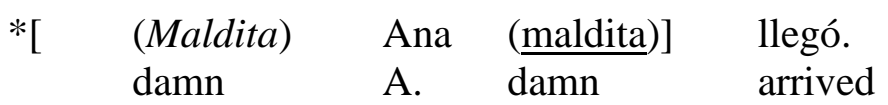

Therefore, for a proper name root to be combined with this type of expressives, the proper name has first to be converted into a predicate by the presence of a $n \mathrm{P}$ selecting Num head, which is exactly what happens with the reviewer's example in (26). But if this is the case, then the string doña Ana has to be reanalyzed as a unit interpreted as a metalinguistic predicate, roughly of the form person referred to as "doña Ana". ${ }^{10}$ It is to this complex object that maldita applies for outputting an expressive nominal phrase that introduces a conventionally implicated meaning, also roughly paraphrased as the proposition that the speaker is in a heightened emotional state regarding the individual referred to as "doña Ana". I think that this meaning is intuitively correct, in which case the reviewer's example in (26) is not about combining two expressives with a proper name, but just one, maldita, which combines with a metalinguistic predicate formed through the presence of a Num head in the underlying structure. ${ }^{11}$ A final piece of evidence in favor of this quotative analysis for the string doña Ana as it occurs in (26) comes from the grammatical alternative to (25b), which basically consists of enclosing the string don Alfredo under quotative marks:

10 Note that this metalinguistic predicate must be distinguished from the original naming predicate, since the individual Ana is called "Ana" not "Doña Ana". But of course, the relevant individual can be addressed in other ways, one of which is "Doña Ana". However, as Nicolás Lo Guercio notes, we cannot entirely reject a different analysis in which we have indeed two expressives, maldita and don, but combined in a different syntactic structure. Concretely, he suggests that an alternative analysis similar to the one that underlies English expressive nominals like that damn John is not implausible. I agree. Perhaps, the most reasonable alternative compatible with my assumptions here is to analyze these particular uses of expressives like epithets and not like expressive attributive adjectives (EAs). As Potts (2005) shows in detail, epithets, unlike EAs, take individuals as semantic arguments, not properties. Yet, in the general case, Spanish epithets, unlike English ones, require that their $e^{a}$-denoting argument surfaces with the preposition de 'of' like in el maldito de Juan lit. 'The damn of Juan'. Still, it is plausible to give an appositive analysis to el maldito Juan, according to which we combine the phrase containing the epithet with the proper name in an appositive relation (e.g., [DP [DP el maldito [NP Ø]] [DP Juan]]). I cannot develop this analytical option here and (dis)confirm it through empirical evidence. This will be a topic for future research. For a recent analysis of epithets in Spanish, see Saab and Carranza (2021, chapter 12) and Orlando and Saab (in press). 


$\begin{array}{llllll}\text { Los "don Alfredo" que conozco } & \text { llegaron } & \text { tarde. } \\ \text { The.PL HON.PL Alfred } & \text { that know.1sG } & \text { arrived } & \text { late }\end{array}$

'The "Mr. Alfred" I know arrived late.'

As Nicolás Lo Guercio (p.c.) correctly points out, that something along these lines is on the right track is further confirmed by the fact that the honorific meaning is fully absent in this example. The clear intuition is that the speaker is talking about individuals who are referred to as "don Alfredo", not that the speaker respects such individual. Period. Therefore, it has to be the case that the string don Alfredo is affected as a unit by the quotation marks.

In sum, the particular interaction among different types of expressives shows that an analysis along the lines proposed in this note, according to which referential and predicative uses of proper names crucially depends on the absence or presence of functional structure within DPs, seems to be essentially on the right track and makes sense of what otherwise looks like a curious casuistic. In this respect, I have shown that the curious distribution of personal articles in modern Catalan and Spanish honorifics are ideal candidates to isolate referential uses of proper names, which cannot have an underlying predicative structure but a referential one.

\section{References}

Acquaviva, Paolo. 2007. The ontological status of names. Ms., University College Dublin.

Bernstein, Judy, Francisco Ordóñez and Francesc Roca. 2019. "On the emergence of personal articles in the history of Catalan." In Miriam Bouzouita, Anne Breitbarth, Lieven Danckaert, and Elisabeth Witzenhausen (eds.) Cycles in language change, 88-108. Oxford: Oxford University Press.

Brucart, José María. 2002. "Els determinants." In Jaume Solà (ed.) Gramàtica del Català Contemporani, 1435-1516. Barcelona: Empúries.

Gutzmann, Daniel. 2019. The grammar of expressivity. Oxford: Oxford University Press.

Matushansky, Ora. 2006. "Why rose is the rose: on the use of definite articles in proper names." Empirical Issues in Syntax and Semantics 6: 285-307.

Matushansky, Ora. 2008. "On the linguistic complexity of proper names." Linguistics and Philosophy 31: 573-627. https://doi.org/10.1007/s10988-008-9050-1

Orlando, Eleonora and Andrés Saab. In press. "Epítetos e insultos de grupo en español. Sobre una ambigüedad sintáctica y sus implicaciones semánticas." Sudies in Hispanic and Lusophone Linguistics.

Potts, Christopher. 2005. The logic of conventional implicature. Oxford: Oxford University Press.

Saab, Andrés and Fernando Carranza. 2021. Dimensiones del significado. Una introducción a la semántica formal. Buenos Aires: SADAF.

Saab, Andrés and Nicolás Lo Guercio. 2020. "No name: The allosemy view." Studia Linguistica 74(1): 60-97. https://doi.org/10.1111/stul.12116 